\title{
Artificial Intelligence in Performance Analysis of Load Frequency Control in Thermal-Wind-Hydro Power Systems
}

\author{
K. Jagatheesan \\ Graduate Student Member IEEE, Assistant Professor, \\ Dept. of Electrical and Electronics Engineering \\ Mahendra Institute of Engineering and Technology \\ Namakkal, Tamilnadu, INDIA

\section{B. Anand} \\ Member IEEE, Associate Professor \\ Dept. of Electrical and Electronics Engineering \\ Hindusthan college of Engineering and Technology \\ Coimbatore, Tamilnadu, INDIA
}

\author{
Nilanjan Dey \\ Dept. of CSE, Bengal College of Engineering \& \\ Technology, West Bengal, India
}

Amira S. Ashour

Department of Electronics \& Electrical Communications Engineering, Faculty of Engg., Tanta Univ., EGYPT. College of CIT, Taif University, KSA

\begin{abstract}
In this article, Load Frequency Control (LFC) of three area unequal interconnected thermal, wind and Hydro power generating units has been developed with ProportionalIntegral (PI) controller under MATLAB/SIMULINK environment. Further, the PI controller gains values that optimized using trial and error method with two different objective functions, namely the Integral Time Square Error (ITSE) and the Integral Time Absolute Error (ITAE). The performance of ITAE objective function based PI controller is compared with the ITSE objective function optimized PI controller. Analysis reveals that the ITSE optimized controller gives more superior performance than ITAE based controller during one percent Step Load Perturbation (1\% SLP) in area 1 (thermal area). In addition, Proportional-Integral -Derivative (PID) controller is employed to improve the same power system performance. The controller gain values are optimized using Artificial Intelligence technique based Ant Colony Optimization (ACO) algorithm. The simulation performance compares the ACO-PID controller to the conventional PI. The results proved that the proposed optimization technique based the ACO-PID controller provides a superior control performance compared to the PI controller. As the system using the ACO-PID controller yield minimum overshoot, undershoot and settling time compared to the conventional PI controlled equipped system performance.
\end{abstract}

Keywords-Cost curve; Interconnected Power system; Load Frequency Control (LFC); Objective Function; Performance Index; Proportional-Integral controller

\section{INTRODUCTION}

Generally, in power generating units another form of energy is converted into electric energy or mechanical energy. Mechanical energy is converted into electrical energy by the use of electrical generator. The thermal power system converts heat energy into electrical energy. While, the gravitational/ falling force of water is converted into electric power via the use of hydro power plant. In addition, the wind power is extracted from the air flow using wind turbines.

The quality of generating power supply from the generating unit depends on the consistency in voltage and frequency during sudden or continuous load demand. But practically maintaining the mentioned quantity/ parameters within the specified or nominal value is very complex as the load is continuously varied due to enormous growth in industries. In order to overcome this drawback power generating units are interconnected through tie-line [1-6]. During normal loading conditions each area carries its own load and keep the system parameters within the specified limit. When sudden load demand occurs in any one of the interconnected power system, suddenly the system parameters oscillate. At the same time remaining power system share the power (through tie-line) between them to maintain system stability [11-13].

Several control techniques have been proposed for the LFC of power systems to keep the system parameters at their specified value during sudden and normal loading conditions [1-10]. Literatures show that the system performance depends on both the employed controller and the selected objective function for tuning the controller parameters. In addition, it is clearly shown that many control strategies have been developed for load frequency control/Automatic Generation control application through the past few years. Such control strategies are as: Parameter-plane technique [15], Lyapunov Technique [16], Continuous and Discrete mode Optimization [18], Optimal Control theory [19], Adaptive Controller [20], Variable Structure Control(VSC) [22], Decentralized controller [21], Conventional controller [23], Fuzzy Logic controller [5], Classical Controller [1], Integral Controller [1], Bat inspired algorithm (BID) [26], Beta Wavelet Neural Network (BWNN) [27], Teaching Learning Based Optimization (TLBO) [28], Firefly Algorithm [29], Cuckoo Search [30], on Multi Input 
Multi Output (MIMO) [36], etc. Table I reports the different control strategies related to LFC/AGC.

TABLE I. DIFFERENT CONTROL STRATEGIES IN LFC/AGC APPLICATIONS

\begin{tabular}{|c|c|c|}
\hline Control Strategy & Author & Year \\
\hline Parameter-plane technique [15] & Nanda and kaul & 1978 \\
\hline Lyapunov Technique [16] & Tripathy et al. & 1982 \\
\hline $\begin{array}{l}\text { Continuous and Discrete mode } \\
\text { Optimization [17] }\end{array}$ & Nanda et al & 1983 \\
\hline Optimal Control theory [18] & $\begin{array}{l}\text { Kothari and } \\
\text { Nandha }\end{array}$ & 1988 \\
\hline Adaptive Controller [19] & Pan and Lian & 1989 \\
\hline $\begin{array}{l}\text { Variable Structure Control(VSC) } \\
\text { [20] }\end{array}$ & Das et al. & 1991 \\
\hline Decentralized controller [21] & $\begin{array}{l}\text { Aldeeen and } \\
\text { Marsh }\end{array}$ & 1991 \\
\hline Conventional controller [4] & Nandha et al. & 2006 \\
\hline Fuzz Logic controller [5] & $\begin{array}{l}\text { Anand and Ebinzer } \\
\text { Jeyakumar }\end{array}$ & 2009 \\
\hline Classical Controller [1] & $\begin{array}{l}\text { Nandha and } \\
\text { Mishra }\end{array}$ & 2010 \\
\hline Integral Controller [2] & $\begin{array}{l}\text { Jagatheesan and } \\
\text { Anand }\end{array}$ & 2012 \\
\hline Particle Swarm Optimization [3] & $\begin{array}{l}\text { Naresh kumari and } \\
\text { Jha }\end{array}$ & 2013 \\
\hline Gradient Descent Method [3] & $\begin{array}{l}\text { Naresh kumari and } \\
\text { Jha }\end{array}$ & 2013 \\
\hline Conventional controller [23] & $\begin{array}{l}\text { Jagatheesan and } \\
\text { Anand }\end{array}$ & 2014 \\
\hline Ant Colony Optimization [24] & $\begin{array}{l}\text { Jagatheesan and } \\
\text { Anand }\end{array}$ & 2014 \\
\hline $\begin{array}{l}\text { Stochastic Particle Swarm } \\
\text { Optimization }[25,34]\end{array}$ & $\begin{array}{l}\text { Jagatheesan and } \\
\text { Anand }\end{array}$ & 2014 \\
\hline Firefly Algorithm [29] & Dey et al. & 2014 \\
\hline Cuckoo Search [30] & Dey et al. & 2014 \\
\hline Bat inspired algorithm (BID) [26] & Das et al. & 2015 \\
\hline $\begin{array}{l}\text { Beta Wavelet Neural Network } \\
\text { (BWNN) [27] }\end{array}$ & $\begin{array}{l}\text { Francis and } \\
\text { Chidambaram }\end{array}$ & 2015 \\
\hline $\begin{array}{l}\text { Teaching Learning Based } \\
\text { Optimization (TLBO) [28] }\end{array}$ & Sahu et al. & 2015 \\
\hline
\end{tabular}

The rest of the paper is organized as follows: Section II, describes the proposed system modeling. The proper controller and the design analysis are presented in section III. In section IV, simulations and results are obtained using the ITSE and ITAE objective functions tuned PI controller to the system. Finally, the conclusion is presented in Section V.

\section{SYSTEM MODELING}

The examined power system consists of three areas interconnected power system for: Thermal (Area 1), Wind (Area 2) and Hydro power (Area 3) system; respectively. The transfer function model of the multi-area power system is shown in Figure 1. The nominal parameters of thermal and hydro power system parameters are taken from $[5,10]$ and the wind power system parameters are taken from [3, 14]. The thermal power system is equipped with an appropriate governor unit, single stage reheat unit and speed regulator components. Similarly, hydro power plant equipped with mechanical governor and speed regulator components.

\section{A. Hydro and thermal power system}

The thermal power system is equipped with appropriate single stage reheater unit. The thermal power system converts high temperature and high pressure steam into useful mechanical energy by the use of turbine and generator.

Hydro power plant is equipped with suitable electric governor and provides better performance over the mechanical governor. The kinetic energy storage stored in hydro power plant is converted into electric power with the help of hydro turbine and generator.

\section{B. Wind power system}

The 35MW capacity of wind power system is interconnected to multi-area interconnected power system. Wind power is extracted from wind by the use of wind turbine. As the transfer function model of Wind Energy Conversion System (WECS) is developed via assuming constant wind speed. The proper selection of natural frequency $\omega_{n}$ and damping factor $\varsigma$ gives the second order dynamics of WECS $[3,14]$. Two poles and one zero transfer function of the WECS are given by:

$$
H_{p t}(s)=\frac{\left.K_{p t} \cdot\left(T_{Z} S+1\right)\right)}{\left(T_{\Sigma} S+1\right)\left(T_{p t} S+1\right)}
$$




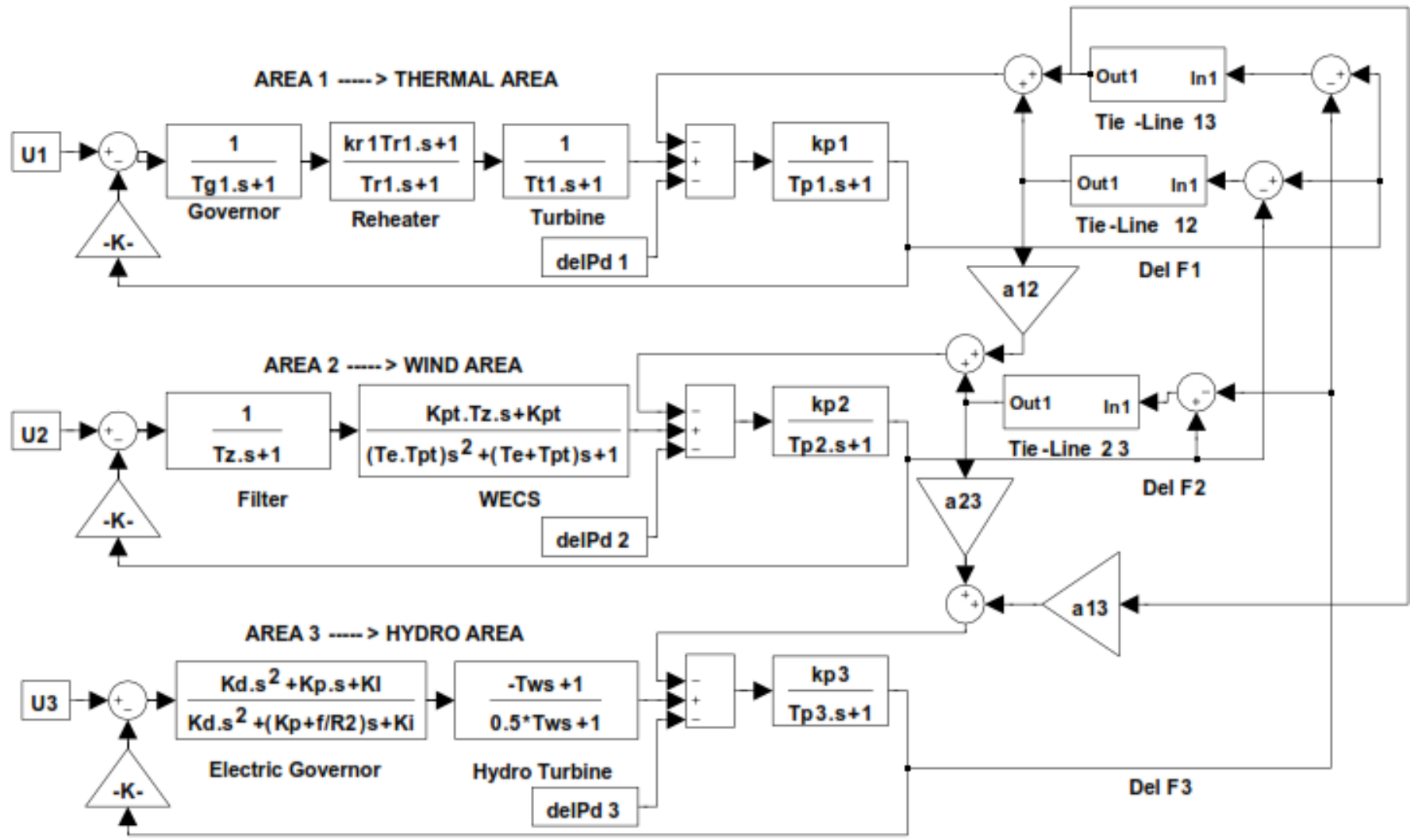

Fig. 1. Transfer function model of three areas Thermal-Wind-Hydro power system

\section{CONTROLLER SYSTEM}

System response yields more damping oscillations and larger steady state error during the sudden load disturbance. Introduction of the controller in feedback control system modifies the error signal and achieve better control action. Additionally, the transient response and steady state operation of the system is modified with the help of the controller [4, 6]; the proportional controller amplifies the error signals and increases the loop gain of the system. The overall system performance is improved based on the control design of the system. As in $[1,2,35]$, the integral controller reduces or eliminates the steady state error.

The objective function of the examined power system is given by:

Integral Absolute Time Error (IATE)

$$
J_{3}=\int_{0}^{\infty} t\left|\left\{\Delta f_{i}+\Delta P_{\text {tiei-j }}\right\}\right| d t
$$

Integral Time Square Error (ITSE)

$$
J_{2}=\int_{0}^{\infty} t\left(\left\{\Delta f_{i}+\Delta P_{t i e i-j}\right\}\right)^{2} d t
$$

Where,

$\mathrm{e}(\mathrm{t})$ is the error signal, and $d t$ is a small time interval during the sample.
The optimal Proportional and Integral controller gain $\left(\mathrm{K}_{\mathrm{P}}\right.$ and $\mathrm{K}_{\mathrm{I}}$ ) values are obtained via plotting the cost that obtained for various values of controller gain against the Performance index J. Integral controller gain values are optimized using two cost functions. Then, the proportional gain values are optimized by keeping the integral controller gain value constant [4]. The Integral controller and Proportional controller cost curve obtained using ITAE objective function is shown in fig. 2 and 3. The Integral controller and Proportional controller cost curves are obtained using ITAE objective function as illustrated in fig. 4 and 5.

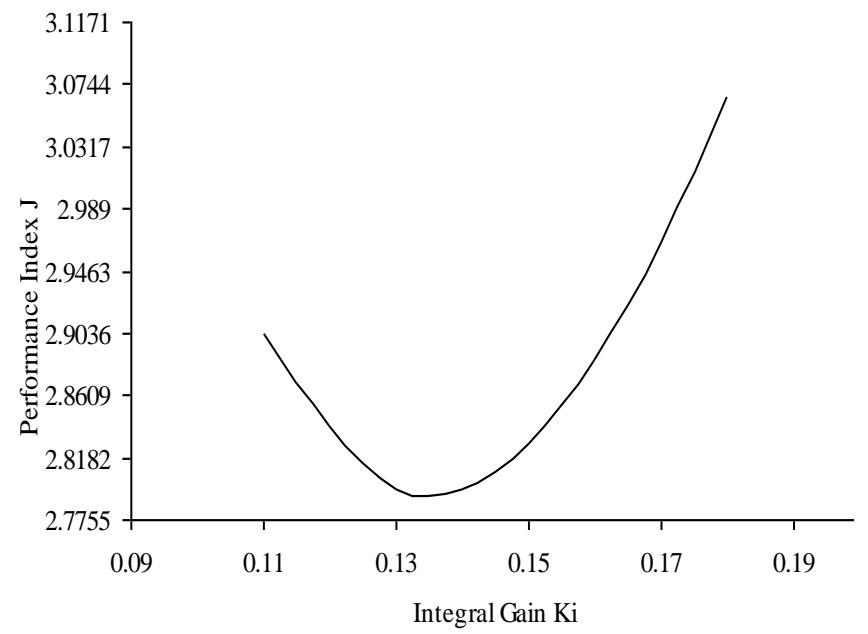

Fig. 2. Cost curve for Integral Gain - ITAE 


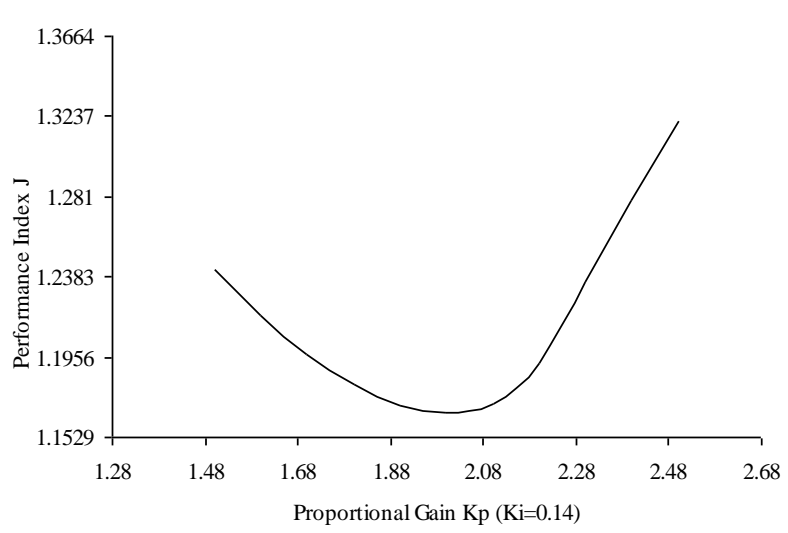

Fig. 3. Cost curve for Proportional Gain - ITAE

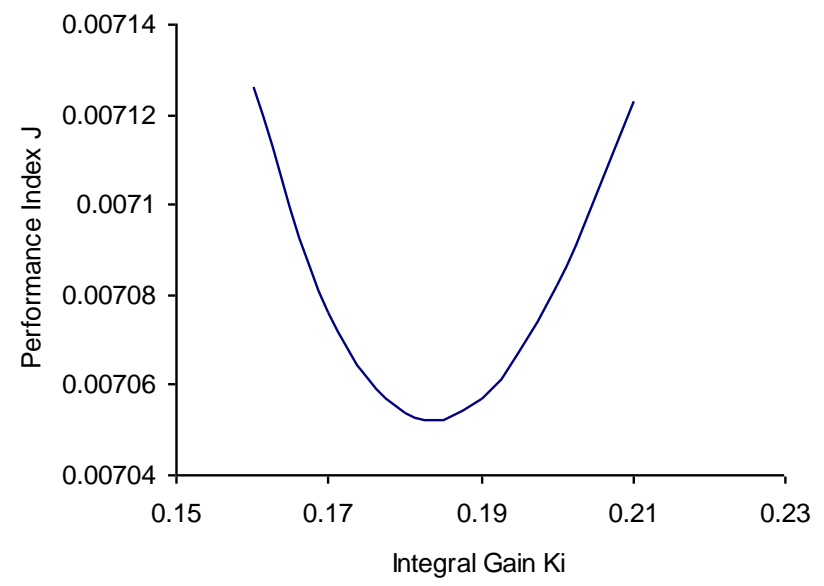

Fig. 4. Cost curve for Integral Gain - ITSE

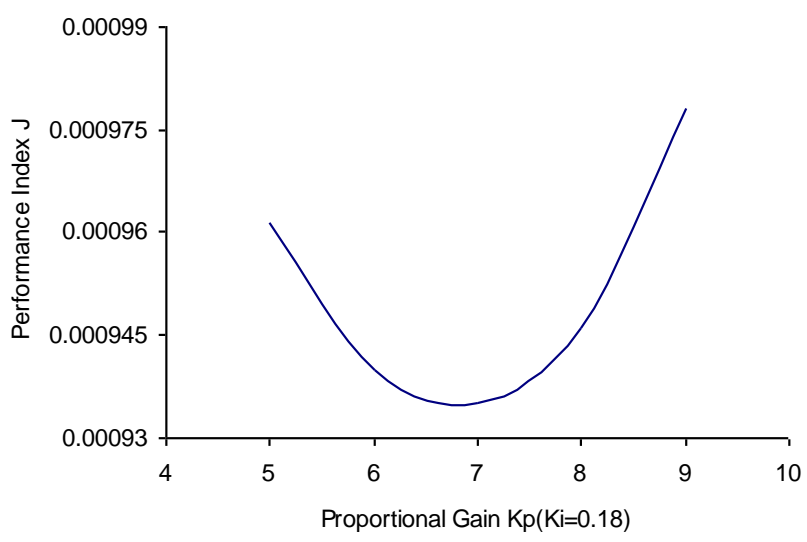

Fig. 5. Cost curve for Proportional Gain - ITSE

Table II provides the values of $\mathrm{P}$ controller gain $\left(\mathrm{K}_{\mathrm{P})}\right.$ and the controller gain $\mathrm{K}_{\mathrm{I}}$ parameters tuned using ITSA and ITAE functions.

TABLE II. TUNED PI PARAMETERS WITH DIFFERENT OBJECTIVE FUNCTION

\begin{tabular}{|c|c|c|c|c|}
\hline \multirow{2}{*}{$\begin{array}{l}\text { Objective } \\
\text { function }\end{array}$} & \multicolumn{4}{|c|}{ Controller } \\
\hline & $K_{I}$ & $J$ & $K_{P}$ & $J$ \\
\hline ITAE & 0.14 & 2.797 & 2 & 1.66 \\
\hline ITSE & 0.18 & 0.007054 & 7 & 0.000935 \\
\hline
\end{tabular}

\section{Ant Colony Optimization TeChNiQues}

There are various meta-heuristic algorithms that can be used is several applications as in [37- 40]. The first metaheuristic based Ant Colony Optimization (ACO) algorithm for hard discrete optimization problem was proposed in early 1990 's. As the foraging behaviors of real ants are considered the basic inspiring source for developing ACO. During the food searching time, initially all ants explore around the surroundings randomly of their nest. As soon as possible ants find a food source, it evaluates the quality and quantity of food source and carries some amount of food back to their nest. Based on the quality and quantity of the food, pheromone quantity laid in the ground varied, it will guide to other ants to find the food source from their nest. This indirect communication between real ants through pheromone chemical is used to find the shortest path between food source and nest [24, 31, 32, 34, 41, 42].

The abovementioned behaviors of artificial ant colonies are used to solve complex discrete optimization problem. The expression of a probability and pheromone updating given by [32].

The transition probability from town $i$ and $j$ for the $\mathrm{k}_{\mathrm{th}}$ ant as follows

$$
p_{i j}(t)=\frac{\tau_{i j}(t)^{\alpha}\left(\eta_{i j}\right)^{\beta}}{\sum_{j \in \text { nodes }} \tau_{i j}(t)^{\alpha}\left(\eta_{i j}\right)^{\beta}}
$$

The value of pheromone versus heuristic information $\eta_{i j}$ is given by:

$$
\eta_{i j}=\frac{1}{d_{i j}}
$$

The global updating rule is implemented in the ant system, where all ants start their tours, pheromone is deposited and updated on all edges based on equation (6) as follows:

$$
\tau_{i j}(t+1)=(1-\rho) \tau_{i j}(t)+\sum_{\begin{array}{c}
k \in \text { colonythat } \\
\text { used edge }(i, j)
\end{array}} \frac{Q}{L_{k}}
$$

Where, $\mathrm{P}_{\mathrm{ij}}$ is the probability between the town $i$ and $j$,

$\tau_{i j}$ denotes the pheromone associated with the edge joining cities $i$ and $j$,

$\mathrm{d}_{\mathrm{ij}}$ is the distance between cities $i$ and $j$, as $j$ is a constant,

$\mathrm{L}_{\mathrm{k}}$ is the length of the tour performed by $\mathrm{K}_{\mathrm{th}}$ ant,

$\alpha, \beta$ are constant values that find the relative time between pheromone and heuristic values on the decision of the ant,

$\rho$ is the evaporation rate. 
In this study these parameters are selected as follows: Number of ants $=50$, pheromone $(\tau)=0.6$, evaporation rate $(\rho)$ $=0.95$ and number of iterations $=100$.

\section{DYNAMIC RESPONSE ANALYSIS}

The transfer function model of investigating the power system is developed using the MATLAB/SIMULINK environment. Initially, the system is equipped with integral controller in all areas with one percent SLP in area 1. The trial and error method is used to optimize the Integral gain values. Different performance index values are tabulated with various integral gain values and cost curve is plotted (Performance Index versus Integral Gain) as illustrated in figures 2 and 4 for two different objective functions. After that system is equipped with the PI controller, the proportional gain values are optimized via keeping the integral gain constant in all areas. Various proportional gain values are noted with different values of performance index and cost curves (Performance Index versus Proportional Gain) are plotted for two different objective functions.

\section{A. Performance Comparison PI controller with two different objective functions}

The dynamic performance of the proposed power system is compared with two different objective function optimized PI controller. The performance of power systems is obtained by considering one percent Step Load Perturbation in a thermal area (Area 1). Frequency deviations (delF1, delF2 and delF3), tie-line power flow between interconnected area (delPtie12, delPtie13 and delPtie23) and area control error(ACE1, ACE2 and ACE3) are shown in figures 6-14.

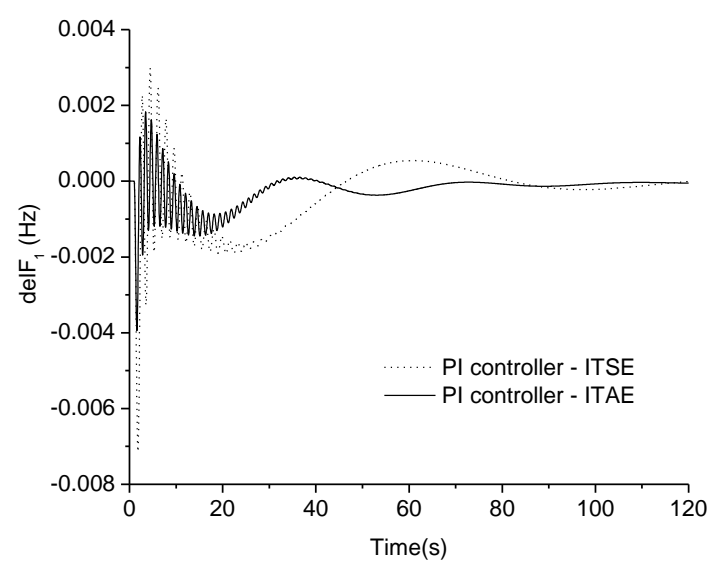

Fig. 6. Frequency deviations (delF1) for $1 \%$ SLP in area 1

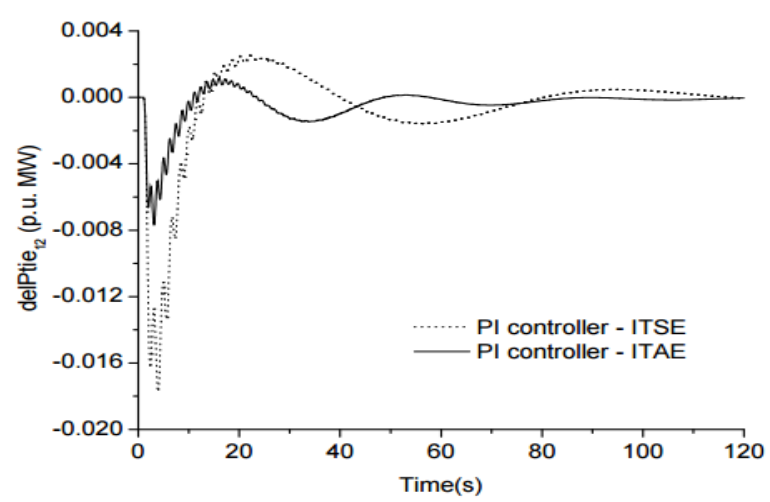

Fig. 7. Tie-line power deviations (delPtie12) for $1 \%$ SLP in area 1

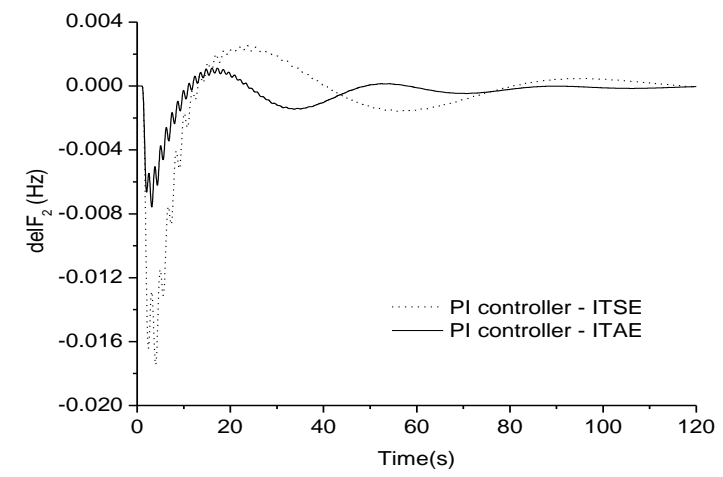

Fig. 8. Frequency deviations (delF2) for $1 \%$ SLP in area 1

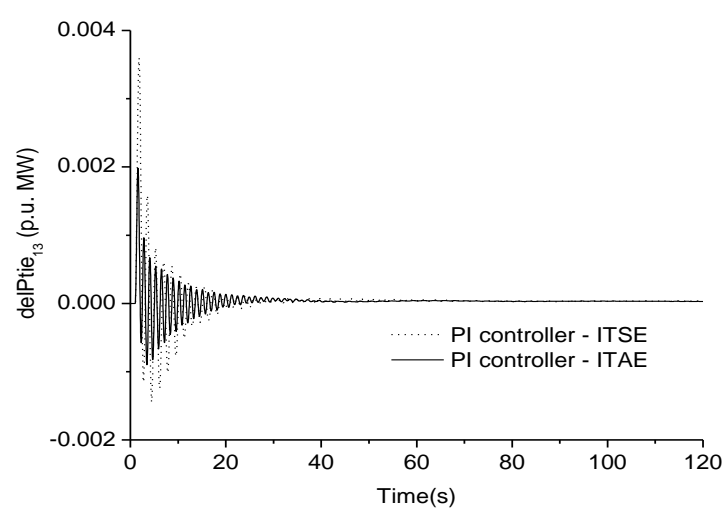

Fig. 9. Tie-line power deviations (delPtie13) for 1\% SLP in area 1 


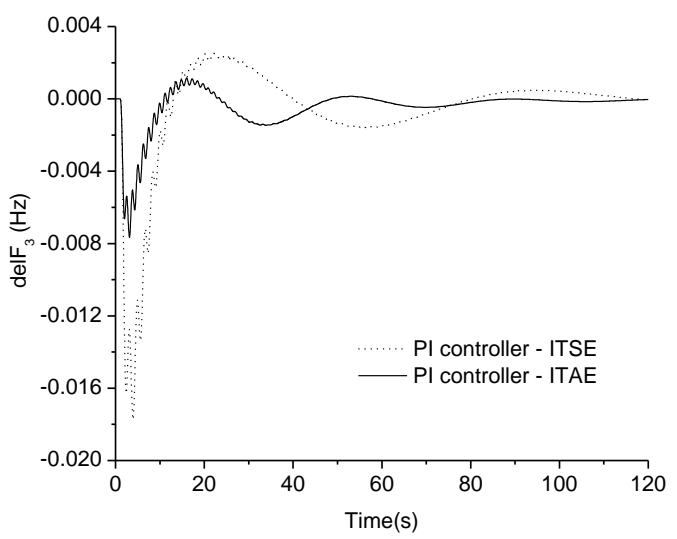

Fig. 10. Frequency deviations (delF3) for $1 \%$ SLP in area 1

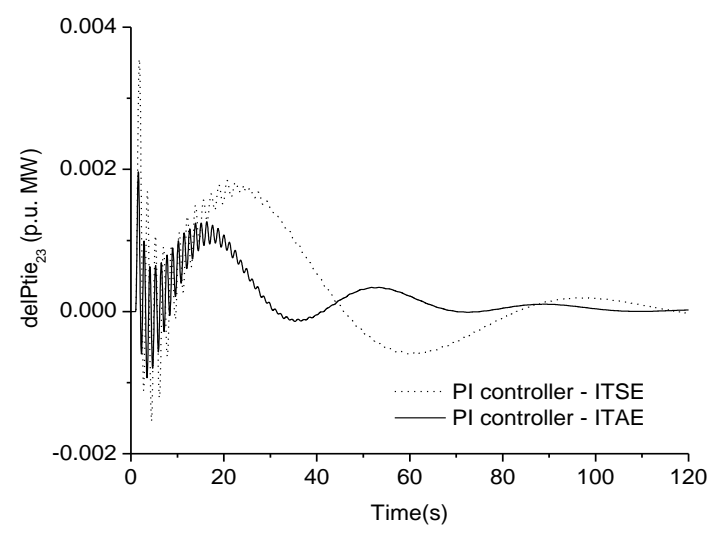

Fig. 11. Tie-line power deviations (delPtie23) for $1 \%$ SLP in area 1

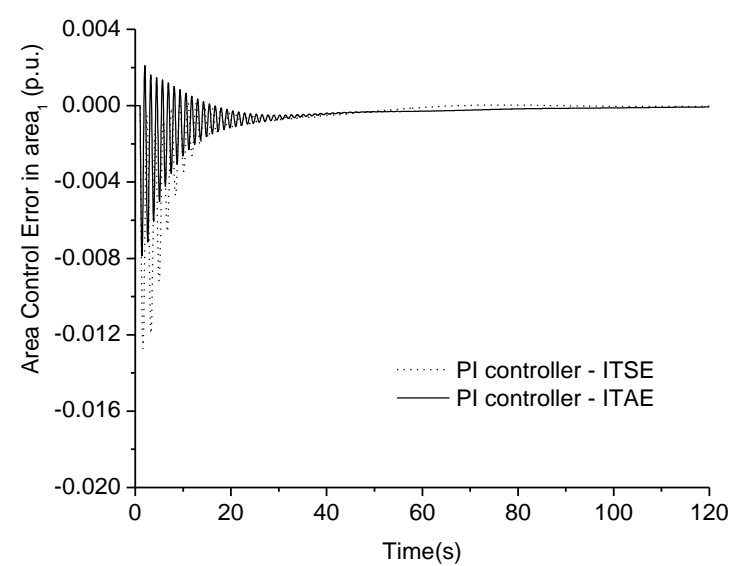

Fig. 12. Area Control Error (ACE1) for $1 \%$ SLP in area 1

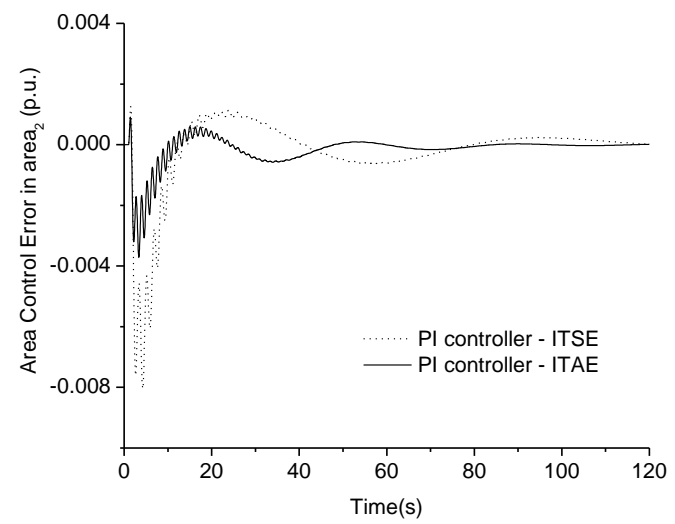

Fig. 13. Area Control Error (ACE2) for 1\% SLP in area 1

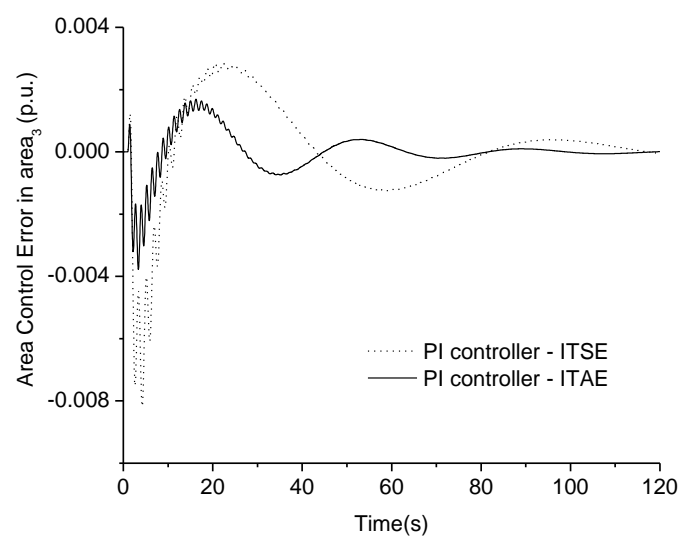

Fig. 14. Area Control Error (ACE3) for 1\% SLP in area 1

It can be clear from figs.6-14 and table III that the system performance is improved in terms of minimum overshoot, undershoot and settling time compared to ITAE objective function optimized PI controller, when the ITSE objective function for the PI controller parameters optimization is used.

TABLE III. PERFoRMANCE OF OBJECTIVE FunCtion

\begin{tabular}{|l|l|l|l|l|l|l|}
\hline & \multicolumn{4}{|l}{ ITAE } & \multicolumn{2}{l|}{ ITSE } \\
\cline { 2 - 7 } & $\boldsymbol{T} \boldsymbol{S}$ & $\boldsymbol{O S}$ & $\boldsymbol{U}$ & $\boldsymbol{T}$ S & $\boldsymbol{O S}$ & $\boldsymbol{U}$ \\
\hline Figure 5 & 79 & 0.0021 & 0.0069 & $\mathbf{6 7}$ & $\mathbf{0 . 0 0 1 1}$ & $\mathbf{0 . 0 0 3 8}$ \\
\hline Figure 6 & 84 & 0.007 & 0.0156 & $\mathbf{8 0}$ & $\mathbf{0 . 0 0 0 1}$ & $\mathbf{0 . 0 0 7 4}$ \\
\hline Figure 7 & 95 & 0.0004 & 0.015 & $\mathbf{8 3}$ & $\mathbf{0 . 0 0 0 0 5}$ & $\mathbf{0 . 0 0 5 8}$ \\
\hline Figure 8 & 35 & 0.0035 & 0.0009 & $\mathbf{3 3}$ & $\mathbf{0 . 0 0 1 8}$ & $\mathbf{0 . 0 0 0 4 6}$ \\
\hline Figure 9 & 111 & 0.016 & 0.0008 & $\mathbf{8 0}$ & $\mathbf{0 . 0 0 0 1 8}$ & 0.006 \\
\hline Figure 10 & 117 & 0.0034 & 0.00097 & $\mathbf{9 8}$ & $\mathbf{0 . 0 0 1 8}$ & $\mathbf{0 . 0 0 0 1 8}$ \\
\hline Figure 11 & 69 & 0.00615 & 0.0114 & $\mathbf{5 9}$ & $\mathbf{0 . 0 0 6}$ & $\mathbf{0 . 0 0 0 4 4}$ \\
\hline Figure 12 & 77 & 0.0011 & 0.0074 & $\mathbf{5 8}$ & $\mathbf{0 . 0 0 0 8}$ & $\mathbf{0 . 0 0 3 1}$ \\
\hline Figure 13 & 113 & 0.0071 & 0.0017 & $\mathbf{7 6}$ & $\mathbf{0 . 0 0 0 8}$ & 0.0030 \\
\hline
\end{tabular}




\section{B. Performance Comparison PI controller with ACO-PID controller}

The response of the power system using the proposed optimization technique based controller is compared to the conventional tuning method based PI controller. The performance of the power systems proposed approach is obtained considering one percent Step Load Perturbation in a thermal area (Area 1). Frequency deviations (delF1, delF2 and delF3), area control error (ACE1, ACE2 and ACE3) and tieline power flow between interconnected area (delPtie12, delPtie13 and delPtie23) are demonstrated in figures 15-23.

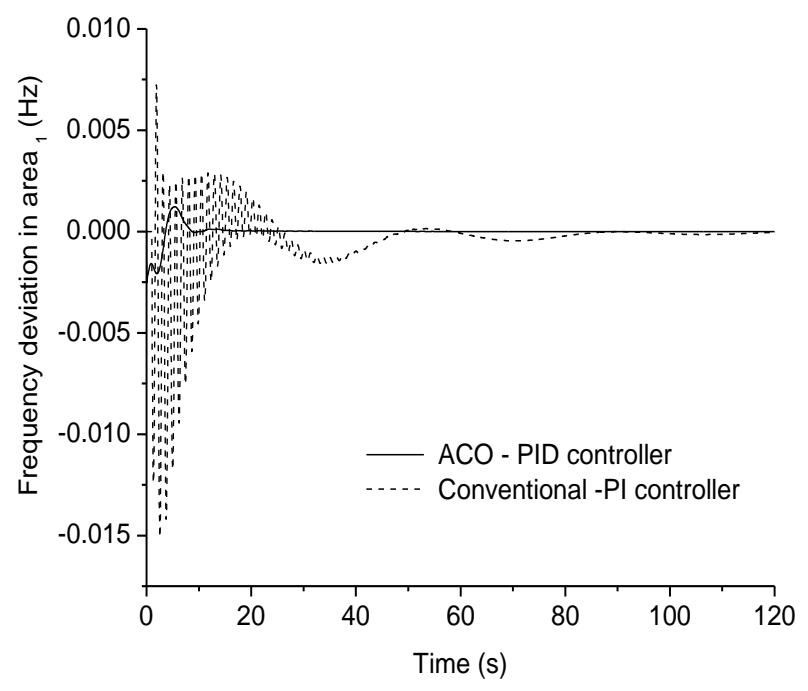

Fig. 15. Frequency deviations (delF1) for $1 \%$ SLP in area 1

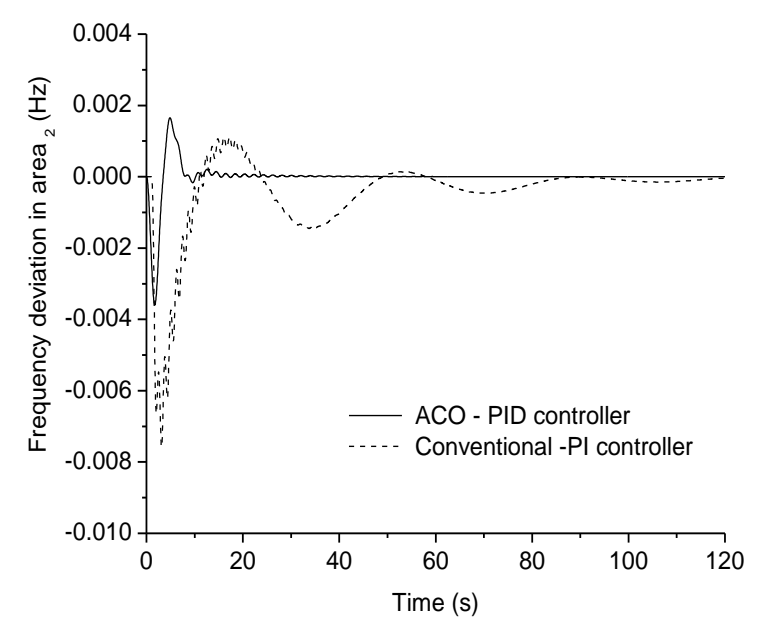

Fig. 16. Frequency deviations (delF2) for $1 \%$ SLP in area 1

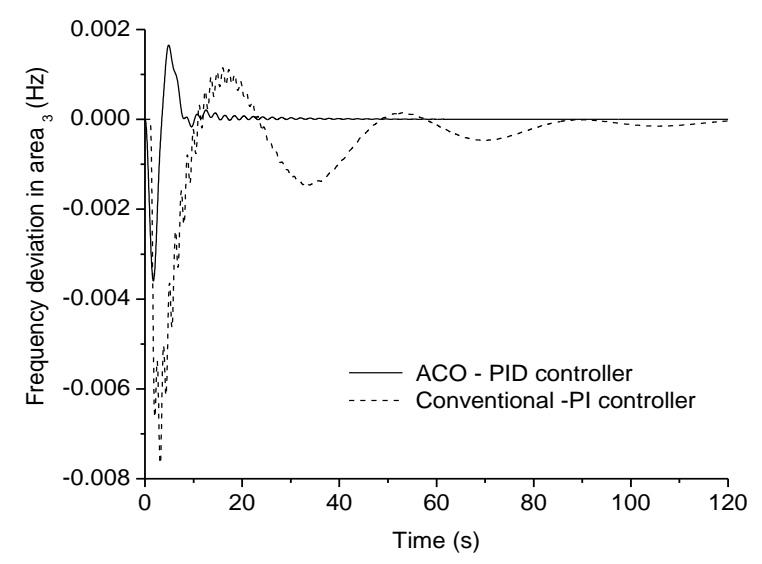

Fig. 17. Frequency deviations (delF3) for $1 \%$ SLP in area 1

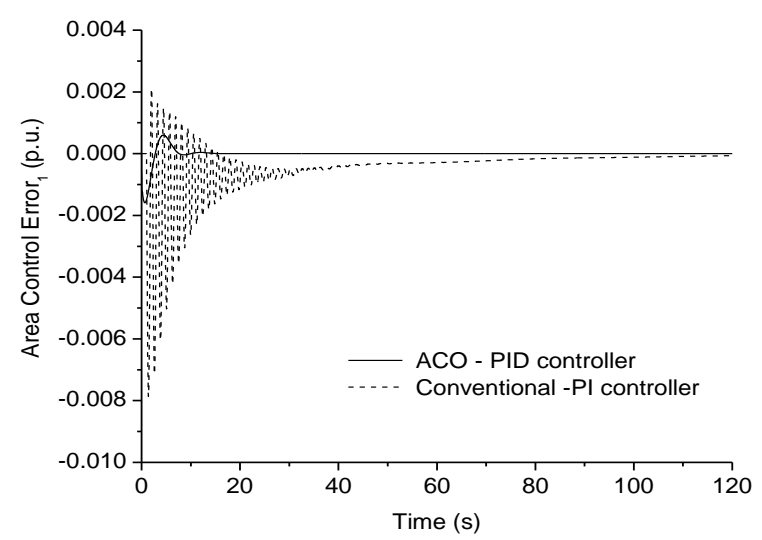

Fig. 18. Area Control Error (ACE1) for $1 \%$ SLP in area 1

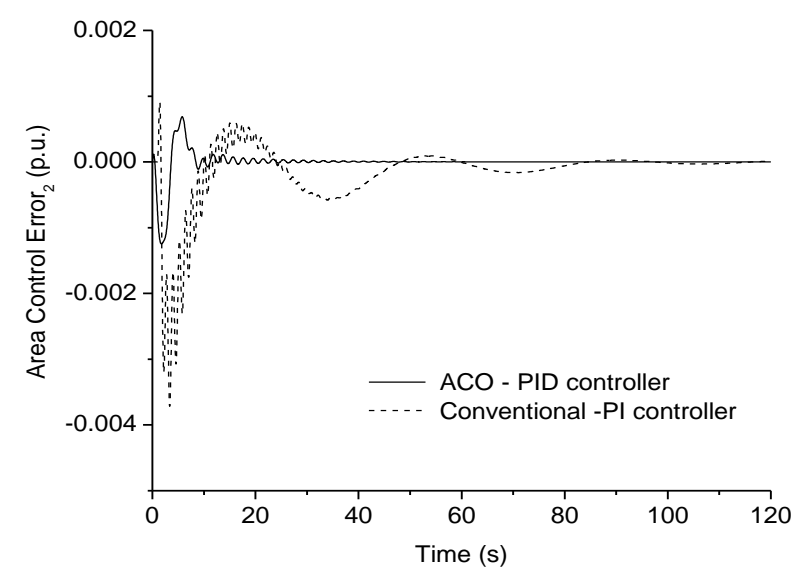

Fig. 19. Area Control Error (ACE2) for $1 \%$ SLP in area 1 


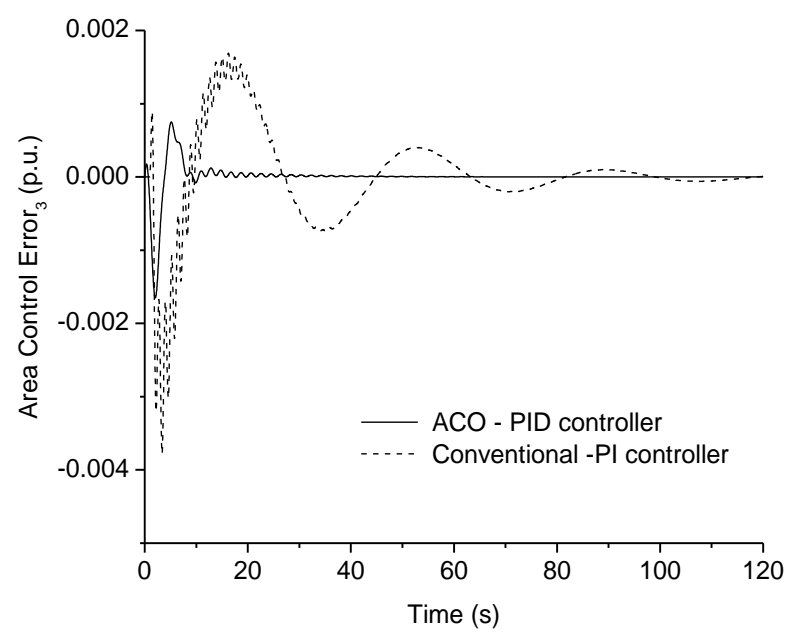

Fig. 20. Area Control Error (ACE3) for $1 \%$ SLP in area 1

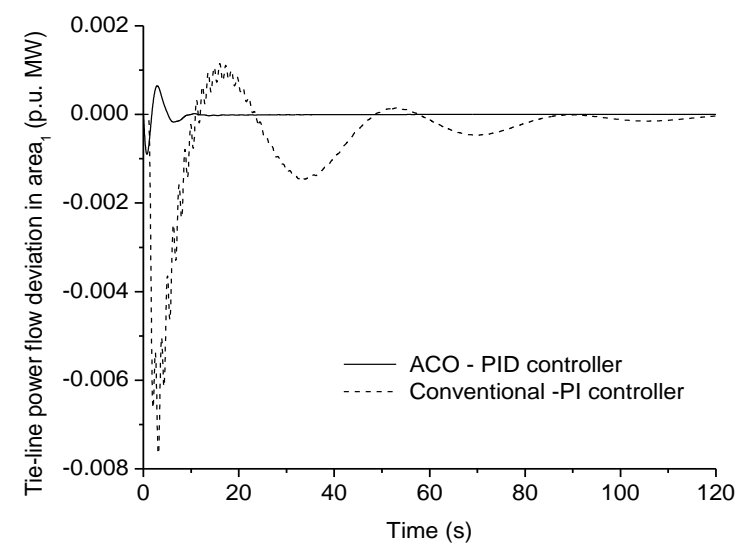

Fig. 21. Tie-line power deviations (delPtie1) for $1 \%$ SLP in area 1

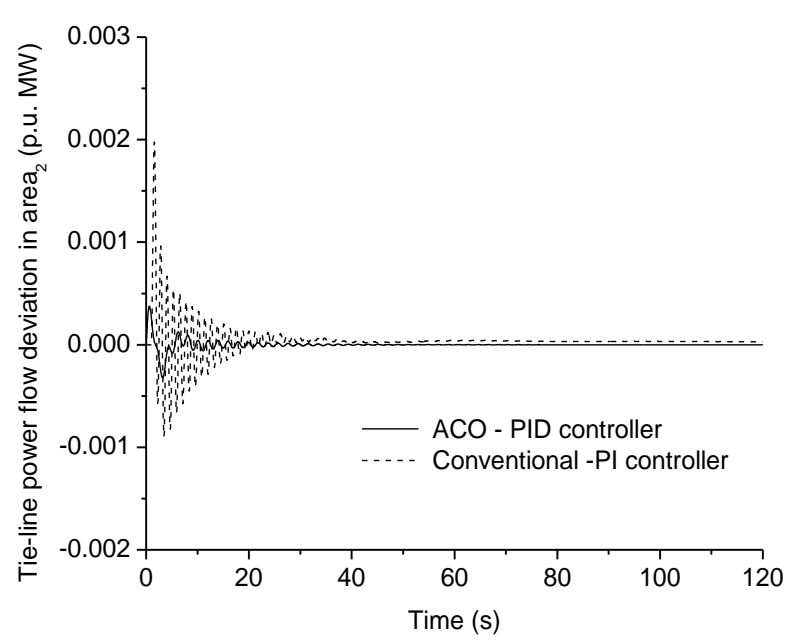

Fig. 22. Tie-line power deviations (delPtie2) for $1 \%$ SLP in area 1

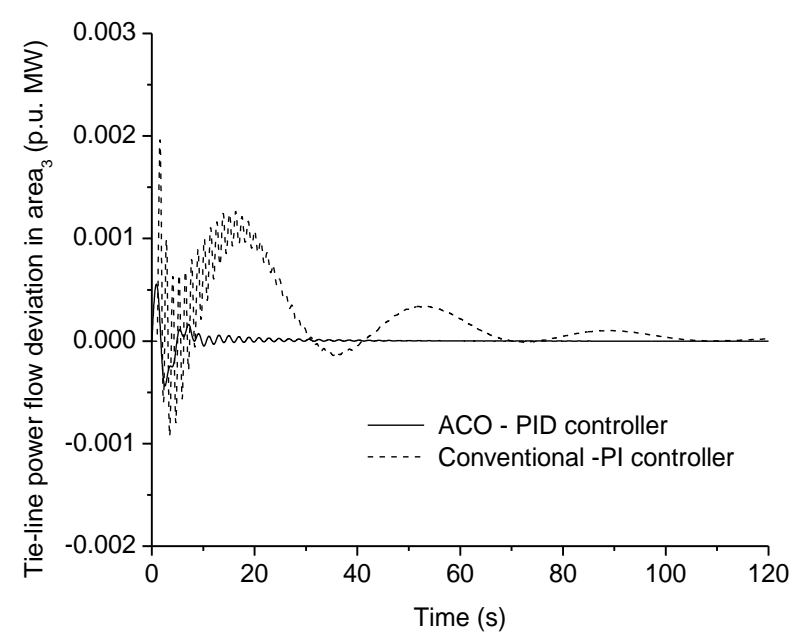

Fig. 23. Tie-line power deviations (delPtie3) for $1 \%$ SLP in area 1

Figs. 15-23 shows the performance comparison of the ACO-PID controller equipped response with conventional PI controller equipped investigated power system. The dotted line shows the conventional PI controller response that produces more damping oscillations nearly up to $100 \mathrm{sec}$ with more settling time, large over and under shoots in the response. The solid line shows the response of ACO-PID controller quipped power system response and it yields less damping oscillations up to $50 \mathrm{sec}$ with minimum over and under shoot with quickly settled response.

It can be observed and concluded from Figs.15-23 and table IV that using the ACO optimized PID controller implemented in the power system, improvise effectively the performance of the power system in terms of minimum overshoot, undershoot and good settling time compared to the conventional tuning method based PI controller response.

TABLE IV. PERFORMANCE OF OBJECTIVE FunCtION

\begin{tabular}{|l|l|l|l|l|l|l|}
\hline & \multicolumn{3}{|l}{ ACO - PID } & \multicolumn{3}{l|}{ Conventional PI controller } \\
\cline { 2 - 8 } & $\boldsymbol{T}$ & $\boldsymbol{O S}$ & $\boldsymbol{U S}$ & $\boldsymbol{T} \boldsymbol{O}$ & $\boldsymbol{O S}$ & $\boldsymbol{U S}$ \\
\hline Figure 15 & 9.46 & 0.0012 & 0.0018 & 47.94 & 0.0069 & 0.012 \\
\hline Figure 16 & 11.4 & 0.003 & 0.001 & 58 & 0.0001 & 0.006 \\
\hline Figure 17 & 14.3 & 0.0012 & 0.0032 & 48.52 & 0.0005 & 0.0062 \\
\hline Figure 18 & 6.59 & 0.00032 & 0.004 & 80.79 & 0.00063 & 0.0069 \\
\hline Figure 19 & 9.13 & $\begin{array}{l}0.00002 \\
6\end{array}$ & 0.0001 & 30.76 & 0.0017 & 0.00057 \\
\hline Figure 20 & 8.24 & 0.00058 & 0.0013 & 53.59 & 0.0019 & 0.0075 \\
\hline Figure 21 & 8.18 & 0.00056 & 0.0014 & 68.68 & 0.0017 & 0.0077 \\
\hline Figure 22 & 10.1 & 0.0004 & 0.0011 & 43.9 & 0.0062 & 0.0028 \\
\hline Figure 23 & $\begin{array}{l}21.0 \\
4\end{array}$ & 0.0073 & 0.0013 & 61.29 & 0.00071 & 0.0029 \\
\hline
\end{tabular}

\section{CONCLUSION}

This paper presents a design of Load Frequency Control (LFC) for multi-area Thermal-Wind-Hydro power systems. Proportional Integral (PI) and Proportional Integral Derivative (PID) controllers are employed to achieve better control performance during the load disturbance. PI Controller gain values are optimized using trial and error method with two 
different objective functions, namely ITAE and ITSE. The PI controller effectiveness is examined and compared by considering one percent Step Load perturbation in the thermal area (Area 1). Simulation results reveal that, ITSE objective function based controller provides much better result (Less Settling Time, Peak over and undershoot, Damping oscillations) compared to ITAE objective function based controller. Further PID controller gain values are optimized using the ACO algorithm and comparisons between PI controller and ACO tuned controller reveal that the ACO-PID controller effectively reduces the electromechanical oscillations, settling time, peak over and undershoots in the system response compared to conventional PI controller equipped power system response. The proposed approach is can also extended to multi-area (more then three areas) with the addition of more renewable energy resource into the same issue of interconnected power system with different bio-inspired algorithms.

\section{REFERENCES}

[1] J. Nandha, and S. Mishra, "A novel classical controller for Automatic generation control in thermal and hydro thermal systems," PEDES, pp.16, 2010 .

[2] K. Jagatheesan, and B. Anand, "Dynamic Performance of Multi-Area Hydro Thermal Power Systems with Integral Controller considering various performance Indices methods," Proceedings of the IEEE International conference of Emerging trends in Science, Engineering and Technology (INCOSET), pp.474-478, 2012.

[3] N. Kumari, and A.N. Jha, " Particle Swarm Optimization and Gradiend descent mmethods for Optimization pf PI controller for AGC of multiarea Thermal-Wind-Hydro power plants," 2013 UKSim 15 $5^{\text {th }}$ International conference on computer modeling and simulation, pp. 536$541,2013$.

[4] J. Nanda, A. Mangla, and S. sanjay," Some New findings on Automatic control of an interconnected hydrothermal system with conventional controllers," IEEE Trans Energy Convers, vol. 21, pp.187-194, 2006.

[5] B. Anand, and A. Jeyakumar, "Fuzzy Logic load frequency Control of hydro-Thermal system with non-Linearities," Int.J.Elec.Power Eng, vol. 3, pp. 112-118,2009.

[6] K. Chatterjee, "PI controller for Automatic Generation Control Based on Performance Indices," World Academy of Science, Engineering and Technology, vol.75, pp.321-356, 2011.

[7] M.L. Kothari, J. Nanda, and P.S.Satsangi, "Automatic generation control of hydrothermal system considering generation rate constraints," J.Inst.Eng.India, vol.63, pp.289-297, June 1983.

[8] S. kumar, and G. Sharma, "AGC \& AVR of interconnected thermal power system while considering the effect of GRCs." Int.Journal of soft computing and engineering, vol.2, pp.69-74, March 2012.

[9] R. Thottungal, P Anbalagan, "Frequency stabilization in multi area system using HVDC link." Proceedings of the IEEE, pp.590-595, 2006.

[10] B. Anand, and A. Jeyakumar, "Load Frequency control with Fuzzy logic Controller considering Non-Linearities and Boiler Dynamics," ACSE, vol8, pp .15-20, January2009.

[11] O.I. Elgerd, "Electric Energy System Theory: An Introduction," Tata Mc-Graw Hill Publishing company limited,, New York,1970.

[12] I.J. Nagrath, and D.P. Kothari, "Power system engineering," Tata McGraw Hill Publishing Company limited, 1994, New Delhi, India.

[13] M. Iuian, and N.A.Cutululis, "Opticl control of wind energy systems," Ist ed., springer-Verlad, londan, pp.93-145, 2008.

[14] P. Kundur, "Power system stability and control," Tata Mc-Graw Hill Publishing company limited, 1994, New Delhi, India.

[15] J. Nanda, and B.L. Kaul, "Automatic generation control of an interconnected power system," Proc. IEE, vol.125, pp. 385-390, 1978.

[16] S.C.Tripathy, G.S. Hope, and O.P.Malik, "Optimization of loadfrequency control parameters for power systems with reheat steam turbines and governor dead band nonlinearity," IEE Proc., vol.129- Pt.C, pp. 10-16, 1982.

[17] S.C.Tripathy, T.S. Bhatti, C.S.Jha, O.P. Malik, and G.S.Hope, "Sampled data automatic generation control analysis with reheat steam turbines and governor dead-band effects," IEE transactions on power apparatus and systems, Vol.PAS-103, pp.1045-1051, 1984.

[18] J. Nanda, M.L. Kothari, and P.S.Satsangi, "Automatic generation control of an interconnected hydrothermal system in continuous and discrete modes considering generation rate constraints," IEE proc., vol.130, Pt. D, pp. 17-27, 1983.

[19] M. L. Kothari, and J. Nanda, "Application of optimal control strategy to automatic generation control of a hydrothermal system," IEE proceedings, Vol.135, Pt.D, pp.268-274, 1988.

[20] C.T. Pan, and C..M. Liaw, "An adaptive controller for power system load-frequency control,' IEEE transaction on power systems, Vol.4, No.1, pp: 122-128, 1989.

[21] M. Aldeeen, and J.F. Marsh, "Decentralized proportional-plus-integral design method for interconnected power systems," IEE Proceedings-C, vol.138, pp. 263-274, 1991.

[22] S. Das, M. L. Kothari, D. P. Kothari, and J. Nanda, " Variable structure control strategy to automatic generation control of interconnected reheat thermal system, IEE proceedings-D , vol. 138, pp.579-585,1991.

[23] K. Jagatheesan, and B. Anand, " Load frequency control of an interconnected three area reheat thermal power systems considering non linearity and boiler dynamics with conventional controller", Advances in Natural and Applied Science, ISSN: 1998-1090, vol.8, pp.16-24, 2014.

[24] K. Jagatheesan, and B. Anand, "Automatic Generation Control of Three Area Hydro-Thermal Power Systems considering Electric and Mechanical Governor with conventional and Ant Colony Optimization technique", Advances in Natural and Applied Science, ISSN: 19981090, vol.8, pp.25-33, 2014.

[25] K. Jagatheesan, B. Anand, and M.A. Ebrahim, "Stochastic Particle Swarm Optimization for tuning of PID Controller in Load Frequency Control of Single Area Reheat Thermal Power System", International Journal of Electrical and Power Engineering, ISSN: 1990-7958, vol.8, pp.33-40, 2014.

[26] P. Dash, L. C. Saikia, and N. Sinha, "Automatic generation control of multi area thermal system using Bat algorithm optimized PD-PID cascade controller," Electric power and Energy systems, vol.68, pp. 364$372,2015$.

[27] R. Francis, and I.A. Chidambaram, " Optimized PI+ load-frequency controller using BWNN approach for an interconnected reheat power system with RFB and hydrogen electrolyser units," Electric power and Energy systems, vol.67, pp. 381-392, 2015.

[28] B. K. Sahu, S. Pati, P. K. Mohanty, and S. Panda, " Teaching-learning based optimization algorithm based fuzzy-PID controller for automatic generation control of multi-area power system," Applied Soft Computing, vol.27, pp. 240-249, 2015.

[29] N. Day, S. Samanta, S. Chakraborty, A. Das, S. S. Chaudhuri, and J.S. Suri, "Firefly Algorithm for Optimization of Scaling Factors during Embedding of Manifold Medical Information: An Application in Ophthalmology Imaging," Journal of Medical Imaging and Health Informatics, vol. 4, pp. 384-394, 2015.

[30] N. Dey, S. Samanta, X. S. Yang, S. S. Chaudhri, and A. Das, "Optimization of Scaling Factors in Electrocardiogram Signal Watermarking using Cuckoo Search," International Journal of BioInspired Computation (IJBIC), vol. 5, pp. 315-326, 2014.

[31] K. Jagatheesan, B. Anand, and N. Dey, "Automatic generation control of Thermal-Thermal-Hydro power systems with PID controller using ant colony optimization," International Journal of Service Science, Management, Engineering, and Technology, vol.6, pp. 18-34, 2015.

[32] M. Omar, M. Solimn, A.M. Abdel ghany, and F. Bendary, "Optimal tuning of PID controllers for hydrothermal load frequency control using ant colony optimization," International journal on electrical engineering and informatics, vol.5, pp. 348-356, 2013.

[33] N. Dey, S. Samanta, X-S. Yang, S. S. Chaudhri, and A. Das, "Optimisation of Scaling Factors in Electrocardiogram Signal Watermarking using Cuckoo Search", International Journal of BioInspired Computation (IJBIC), vol 5, pp-315-326, 2013. 
[34] S. Samanta, S. Acharjee, A. Mukherjee, D. Das, and N. Dey, "Ant Weight Lifting Algorithm for Image Segmentation," 2013 IEEE International Conference on Computational Intelligence and Computing Research(ICCIC), pp.1-5, 2013.

[35] S. Acharjee, S. Chakraborty, W. Karaa, A. Azar, and N. Dey, "Performance Evaluation of Different Cost Functions in Motion Vector Estimation" , International Journal of Service Science, Management, Engineering, and Technology (IJSSMET), IGI Global, vol. 5, pp. 1- 21, 2014 .

[36] S. Chowdhuri, S. Chakraborty, N. Dey, M. M. Salem, A. T. Azar, Sheli S. Chaudhury, and P. Banerjee," Recent Research on Multi Input Multi Output (MIMO) based Mobile ad hoc Network: A Review", International Journal of Service Science, Management, Engineering, and Technology (IJSSMET), IGI Global, vol. 5, pp. 54-65, 2014.

[37] W. Karaa, A.S. Ashour, D. Ben Sassi, P. Roy, N. Kausar, and N. Dey, "MEDLINE Text Mining: An Enhancement Genetic Algorithm based Approach for Document Clustering, Applications of Intelligent Optimization in Biology and Medicine: Current Trends and Open Problems," In book: Applications of Intelligent Optimization in Biology and Medicine:Current Trends and Open Problems, Springer, Chapter 10, 2015.
[38] S. Samanta, N. Dey, P. Das, S. Acharjee, and S. S. Chaudhuri, "Multilevel Threshold Based Gray Scale Image Segmentation using Cuckoo Search", International Conference on Emerging Trends in Electrical, Communication And Information Technologies -ICECIT, Dec 12-23, 2012,

[39] S. Chakraborty, A. K. Pal, N. Dey, D. Das, and S. Acharjee, "Foliage Area Computation using Monarch Butterfly Algorithm," 2014 International Conference on Non Conventional Energy (ICONCE 2014), JIS college of Engineering, Kalyani, January 16-17, 2014.

[40] S. Chakraborty, S. Samanta, A. Mukherjee, N. Dey, and S. S. Chaudhuri "Particle Swarm Optimization Based Parameter Optimization Technique in Medical Information Hiding", 2013 IEEE International Conference on Computational Intelligence and Computing Research(ICCIC), Madurai, Dec . 2013.

[41] S. Samanta, S. Acharjee, A. Mukherjee, D. Das, and N. Dey, "Ant Weight Lifting Algorithm for Image Segmentation", 2013 IEEE International Conference on Computational Intelligence and Computing Research(ICCIC), Madurai, Dec. 2013.

[42] S. Samanta, S. Chakraborty, S. Acharjee, A. Mukherjee, and N. Dey, "Solving 0/1 Knapsack Problem using Ant Weight Lifting Algorithm", 2013 IEEE International Conference on Computational Intelligence and Computing Research(ICCIC), Madurai, Dec. 2013. 